\title{
The impact of law enforcement on dispensing antibiotics without prescription: a multi- methods study from Saudi Arabia
}

Alian A. Alrasheedy ${ }^{1 *}$, Muath A. Alsalloum ${ }^{1}$, Feras A. Almuqbil ${ }^{1}$, Muaath A. Almuzaini ${ }^{1}$, Bandar S. Aba Alkhayl ${ }^{1}$, Ahmed S. Albishri ${ }^{1}$, Faisal F. Alharbi ${ }^{1}$, Saleh R. Alharbi ${ }^{1}$, Abdullah K. Alodhayb ${ }^{1}$, Abubakr A. Alfadl $^{2}$, Brian Godman ${ }^{3,4,5,6}$, Ruaraidh Hill ${ }^{7}$, Mohammed S. Anaam².

'Uniazah College of Pharmacy, Qassim University' Qassim, 51911 Unaizah, Saudi Arabia. Email: alian-a@hotmail.com; alsalloum.muath@gmail.com; ferasalmuqbil@hotmail.com;

iMuath1014@gmail.com; bandar_s.a@hotmail.com; albeshry72@gmail.com;

f.a.alharbi@hotmail.com; Sal14eh@gmail.com; abdullh.k7@gmail.com

2Department of Pharmacy Practice, Uniazah College of Pharmacy, Qassim University' Qassim, 51911

Unaizah, Saudi Arabia. Email: abubakr13@yahoo.com; drmsa.ucp1437@gmail.com

${ }^{3}$ Strathclyde Institute of Pharmacy and Biomedical Sciences, University of Strathclyde, Glasgow G4

ORE, United Kingdom. Email: Brian.godman@strath.ac.uk

${ }^{4}$ Health Economics Centre, University of Liverpool Management School, Liverpool, UK. Email:

Brian.Godman@liverpool.ac.uk

${ }^{5}$ Division of Clinical Pharmacology, Karolinska Institute, Karolinska University Hospital Huddinge, SE-

141 86, Stockholm, Sweden. Email: Brian.Godman@ki.se

${ }^{6}$ School of Pharmaceutical Sciences, Universiti Sains Malaysia, Penang, Malaysia

${ }^{7}$ Evidence synthesis, Health Services Research, University of Liverpool, Liverpool, UK. Email:

rahill@liverpool.ac.uk

*Author for correspondence: Dr Alian A. Alrasheedy, Uniazah College of Pharmacy, Qassim University' Qassim, 51911 Unaizah, Saudi Arabia. Email: alian-a@hotmail.com

\section{ABSTRACT}

Background and objectives: Dispensing of antibiotics without a prescription (DAwP) has been widely practised among community pharmacies in Saudi Arabia despite being illegal. However, in May 2018, the law and regulations were enforced alongside fines. Consequently, we wanted to evaluate the impact of these changes. Methods: A study was conducted among 116 community pharmacies in two phases. Pre-law enforcement phase between December 2017 and March 2018 and a post-law enforcement phase a year later. Each phase consisted of a cross-sectional questionnaire-based survey and a simulated client method (SCM). In the SCM, clients presented with either pharyngitis or urinary tract infections (UTI). In SCM, for each phase, all 116 pharmacies were visited with one of the scenarios. Results: Before the law enforcement, $70.7 \%$ reported that DAwP was common with $96.6 \%$ and $87.7 \%$ of participating pharmacies dispensed antibiotics without a prescription for pharyngitis and UTI respectively. After the law enforcement, only $12.9 \%$ reported that DAwP is still a common practice, with only $12.1 \%$ and $5.2 \%$ dispensing antibiotics without prescriptions for pharyngitis and UTI respectively. Conclusion: law enforcement was effective. However, there is still further scope for improvement. This could include further educational activities with pharmacists, physicians and the public.

Keywords: Dispensing antibiotics without prescriptions, community pharmacy, law enforcement, health policy, Saudi Arabia.

\section{Introduction}

Irrational use of antibiotics is a major factor responsible for the global spread of antimicrobial resistance (AMR) worldwide [1-4], with AMR known to increase morbidity, mortality, and healthcare costs [5-8]. These concerns are leading to multiple initiatives globally, regionally and nationally to improve antibiotic utilisation thereby hoping to reduce AMR rates in the future [2,9-15]. One of the principal activities contributing to the irrational use of antibiotics is the dispensing of antibiotics without a prescription (DAwP) for principally self-limiting conditions such as upper respiratory tract infections (URTIs) as well as urinary tract infections (UTIs) [16-14]. This is because DAwP is frequently associated with inappropriate drug choices, doses and uses [16,25-28], with community pharmacies considered to be the main source for non-prescription antibiotics $[16,19,29,30]$. DAwP is particularly prevalent in LMICs accounting for up to $93 \%$ or more of dispensed antibiotics $[17,19,20,24]$. DAwP is enhanced by high levels of co-payment in low- and middle-income countries (LMICs), difficulties in 
access and affordability of physicians, commercial pressures on pharmacy staff as well as patient and parent pressure on pharmacists to dispense an antibiotic [17,19,20,31-33]. Overall, with up to $100 \%$ of pharmacists dispense antibiotics without a prescription despite legislation banning this in some LMICs $[24,34]$. This situation is very different to for instance Northern European countries with their universal healthcare systems, easier access to physicians, tight control over dispensing activities among community pharmacies and typically reducing antimicrobial utilisation versus LMICs $[26,35-$ 37].

Whilst DAwP is illegal in most countries and despite concerns, it is still widely practiced and estimated to represent more than $50 \%$ of antibiotics consumed worldwide [16-19,21,23,38-40]. DAwP is not limited to low- and middle- income countries (LMICs) as this practice is also seen in high income countries [25,41-43]. Non-prescription sales of antibiotics have been documented in a number of systematic reviews, with Morgan et al. (2011) documenting that DAwP accounted for between 19 to $100 \%$ of total antimicrobial use outside of northern Europe and North America [26]. Ocan et al. (2015) in their review involving LMICs found an overall prevalence of $38.8 \%$ for antimicrobial DAwP [18]. Sakeena et al. (2018) in their systematic review of 50 studies in LMICs also found high rates of nonprescription sales of antibiotics at up to $100 \%$ in some countries [19]. Nepal et al. (2018) in their review also found high rates of DAwP ranging from $7.3 \%$ to $85.59 \%$ with an overall prevalence of $42.64 \%$ [17]. More recently, Auta et al. (2019) in their review and meta-analysis including 38 studies from 24 countries reported that the overall percentage of non-prescription supply of antibiotics was $62 \%[16]$.

In the Middle East, DAwP continues to be a serious problem [21,38,39,44-52]. Similarly, in Saudi Arabia, DAwP has been a long standing issue during the past four decades -despite the fact that DAwP is illegal according to the Law of Practice of Health Professions in Saudi Arabia [52]. The law stipulated that pharmacists are obliged to dispense medicines on prescription only, except those defined as over-the-counter (OTC) and listed in Saudi OTC Formulary as such [53]. However despite this law, many studies conducted across Saudi Arabia over the past years have shown that nonadherence to the law is common [54-62]. For example, Al-Freihi et al. (1987) reported that in 1983, $85 \%$ of community pharmacies in the Eastern Province of Saudi Arabia dispensed antibiotics without prescription [55]. Similarly, in 2001, Al-Ghamdi reported that $82 \%$ of community pharmacists in the Eastern Province dispensed antibiotics over counter [56], with Abdulhak et al. (2011) in Riyadh showing that $77.6 \%$ of community pharmacists handed out antibiotics based on simulated patient requests without a prescription [54]. In their study, Emeka et al. (2014) found that colds and sore throats were the most common reasons for seeking DAwP [61].

These high levels are not surprising since DAwP is not only linked to the lack of legislation that prohibits this practice, but also linked to poor enforcement of these regulations $[20,21,33,34,38,53,63]$. There are also other factors driving DAwP. These include (i) easy access to antimicrobials, (ii) patients' beliefs about antibiotics speeding up their recovery, (iii) commercial pressures on pharmacists, (iv) pressures from patients and parents on pharmacists to dispense antimicrobials, (iv) issues of affordability whereby patients cannot afford to see both a physician and purchase their medicines, (v) the level of education among patients, (vi) long travelling distances to see a physician in a public healthcare centre (PHC) in some countries versus visiting a local pharmacist impacting on potential earnings as well as the cost of travelling, (vii) variable knowledge about antibiotics and AMR among community pharmacists, (viii) and PHCs being out-of-stock of medicines with patients subsequently referred to their local pharmacists anyway to obtain their antibiotics [16,18-21,43,64-69].

The variety of reasons for DAwP have resulted in a range of different activities across countries to try and reduce the extent of self-purchasing of antibiotics along with other measures to improve the rational utilisation of antibiotics within a country, with typically multiple measures and initatives needed to improve future utilisation especially in LMICs [12,13,33,70-72]. Increasing pharmacist's knowledge has also helped reduce DawP, with pharmacists often the first healthcare professional that patients consult with regarding URTIs, UTIs and paediatric diarrhoea [24,40,64,73-76]. The importance of pharmacists as essential players providing information to patients, encouraging the prudent use of antibiotics, and giving proper advice and counselling to patients when dispensing antibiotics, is highlighted by suggested activities and standards promulgated by FIP (International Federation of Pharmacists) and the WHO [29,30]. 
There have been a number of initiatives among countries to enforce the laws governing DAwP including either incentives such as fines, sanctions including the suspension of the license or closure of the pharmacy, or both. Some of these initiatives and their impact where known are documented in Table 1 building on a recent systematic review concerning the impact of legislation to reduce DAwP [77-79].

Table 1 - Examples of activities surrounding increased enforcement of legislation banning DAwP and their impact

\begin{tabular}{|c|c|}
\hline $\begin{array}{l}\text { Albania } \\
{[33,64,80,81]}\end{array}$ & $\begin{array}{l}\text { - The Albanian Ministry of Health recently established a task force to reduce } \\
\text { DAwP through improved inspections and fines for community pharmacists } \\
\text { for abusing the system in view of concerns with their knowledge regarding } \\
\text { antibiotics and concerns with the current extent of DAwP } \\
\text { - In the first months of implementation, over } 100 \text { community pharmacies have } \\
\text { been inspected with approximately one fifth of pharmacies being fined for } \\
\text { dispensing a medicine without a prescription } \\
\text { - The impact of these measures is being monitored in case additional } \\
\text { initiatives are needed to further reduce DAwP }\end{array}$ \\
\hline Brazil [82-85] & $\begin{array}{l}\text { - There have always been restrictions on DAwP among public pharmacies in } \\
\text { Brazil where patients can receive their medicines free of charge. However, } \\
\text { in } 2010 \text { following the increase in multi-resistant KPC (Klebsiella } \\
\text { Pneumoniae Carbapenemase), regulations were tightened for private } \\
\text { pharmacies in which they had to keep a copy of the prescriptions and since } \\
\text { April } 2013 \text { antibiotics have been included in the National Controlled } \\
\text { Substances Management System } \\
\text { - In their study, Santa-Ana-Tellez et al (2013) found a tempering of the } \\
\text { increase in antibiotic consumption in Brazil following tighteneing of the } \\
\text { regulations } \\
\text { In their study, Moura et al (2015) found a significant decrease in overall } \\
\text { antibiotic consumption of } 1.87 \text { DDDs/ one thousand inhabitants per day ( } p< \\
\text { 0.001) among private pharmacies post changes in the legislation but, as } \\
\text { expected, no difference among public pharmacies } \\
\text { In their study, Lopes-Junior et al (2015) among approximately } 3000 \text { private } \\
\text { pharmacies found sales of amoxicillin falling by approximately } 30 \% \text {, } \\
\text { tetracyclines by } 30.5 \%, \text { sulphonamides by } 28.5 \% \text {, and macrolides by } 25 \% \text {, } \\
\text { post legislation despite the general growth in the pharmaceutical market }\end{array}$ \\
\hline Chile $[82,86]$ & $\begin{array}{l}\text { - Chile was one of the first countries in Latin America to introduce greater } \\
\text { enforcement of the law to reduce DAwP among private sector pharmacies } \\
\text { in } 1999 \text { following concerns with increasing antimicrobial consumption and } \\
\text { AMR } \\
\text { - Regulations were enhanced by antibiotics being removed from the list of } \\
\text { medicines having sales incentives in pharmacies } \\
\text { - Antimicrobial consumption decreased from 12.3 DID before the intervention } \\
\text { to } 8.5 \text { DID just after the enforcement (in 2000). This decrease was helped } \\
\text { by the instigation of public information campaigns before and during the } \\
\text { implementation of greater enforcement of the regulations } \\
\text { - However, there has been a slow increase in antimicrobial utilisation since } \\
\text { 2002 suggesting that the effects of the intervention wear off unless } \\
\text { continually monitored and further initiatives introduced when pertinent }\end{array}$ \\
\hline $\begin{array}{l}\text { Colombia } \\
{[82,86,87]}\end{array}$ & $\begin{array}{l}\text { - Colombia started to regulate DAwP in } 2005 \text { in the capital city (Bogotá) } \\
\text { - There was a modest impact on overall retail sales of antibiotics in the three } \\
\text { years (12 quarters) in Colombia (-1.00 DIDs) after the changes in the } \\
\text { regulations } \\
\text { - However, a follow up study five years after implementation of the } \\
\text { regulations found that } 80.3 \% \text { of pharmacies visited still did not comply with } \\
\text { the regulations } \\
\text { - This may help to explain the modest results seen initially prompting calls for } \\
\text { greater enforcement of the law }\end{array}$ \\
\hline
\end{tabular}




\begin{tabular}{|c|c|}
\hline Mexico $[82,88]$ & $\begin{array}{l}\text { - The government in Mexico in } 2010 \text { implemented policies to enforce existing } \\
\text { laws regarding restricting DAwP and only dispensing antibiotics to patients } \\
\text { presenting with a prescription } \\
\text { - The regulation requires antibiotic prescriptions to be retained and registered } \\
\text { in pharmacies, with fines imposes fines on pharmacy owners for non- } \\
\text { compliance } \\
\text { - Overall antibiotic utilisation decreased by } 22.9 \% \text { between } 2007 \text { and } 2012 \text {, } \\
\text { with the trend accelerating after greater enforcement of the legislation } \\
\text { - There was also an appreciable seasonal reduction in the use of penicillins in } \\
\text { Mexico after greater enforcement of the legislation }\end{array}$ \\
\hline Namibia $[89,90]$ & $\begin{array}{l}\text { - There are regulations in place banning DAwP in Namibia helped by universal } \\
\text { access to healthcare including medicines and regular monitoring of } \\
\text { pharmacies } \\
\text { A recent survey in Namibia involving } 100 \text { households in the informal sector } \\
\text { found that parents regularly self-medicated URTIs among their children } \\
\text { including for common colds and influenza } \\
\text { - However, typically treat with cold/flu medication as well as paracetamol and } \\
\text { decongestants rather than antibiotics demonstrating that the regulations are } \\
\text { working. This is helped in Namibia by medicines being free-of-charge in } \\
\text { primary healthcare centres }\end{array}$ \\
\hline $\begin{array}{l}\text { Republic Srpska } \\
{[40,70,91]}\end{array}$ & $\begin{array}{l}\text { - The Republic of Srpska has been active over a number of years to improve } \\
\text { the prescribing and dispensing of antibiotics in ambulatory care following } \\
\text { concerns with high rates of DAwP } \\
\text { - Activities involve continual education of pharmacists and pharmacist } \\
\text { technicians - including published guidelines for pharmacy personnel as well } \\
\text { as continual inspections of community pharmacies since by law antibiotics } \\
\text { are restricted to prescription only medicines in the Republic } \\
\text { Recent studies have shown low levels of DAwP (at } 18.5 \% \text { of pharmacies vs. } \\
58 \% \text { previously) and combined activities including physician and patient } \\
\text { education resulted in the Republic having one of the lowest utilisations of } \\
\text { antibiotics in recent years compared with similar neighbouring countries }\end{array}$ \\
\hline $\begin{array}{l}\text { Turkey } \\
{[78,79,92]}\end{array}$ & $\begin{array}{l}\text { - In 2014, the Turkish health authorities implemented an electronic } \\
\text { prescription system to track prescription data as well as provide feedback to } \\
\text { physicians in line with the } 2014-2017 \text { National Action Plan to enhance the } \\
\text { appropriate use of antibiotics in Turkey given high rates versus other } \\
\text { European countries. This is the comprehensive pharmaceutical "track and } \\
\text { trace" system which tracks medicines from their production to dispensing } \\
\text { - The regulations preventing DAwP include potential fines for pharmacists } \\
\text { following abuse, which have also been in operation since } 2014 \text { aided by the } \\
\text { "track and trace" system } \\
\text { - It is envisaged that future studies will show an appreciable decrease in } \\
\text { DAwP in Turkey following these changes with enhanced monitoring of the } \\
\text { prescribing and dispensing chain }\end{array}$ \\
\hline $\begin{array}{l}\text { Venezuela } \\
{[82,86]}\end{array}$ & $\begin{array}{l}\text { - In 2006, Venezuela implemented a policy to reduce DAwP among three } \\
\text { groups of antibiotics namely macrolides, quinolones and third generation } \\
\text { cephalosporins, without any public awareness campaigns } \\
\text { There was though no change in their utilisation patterns with enforcement } \\
\text { made via only formal government publications and not followed up for } \\
\text { instance with any increase pharmacy supervision or any pharmacy closures } \\
\text { or financial sanctions for non-compliance }\end{array}$ \\
\hline Vietnam [72] & $\begin{array}{l}\text { - Three interventions and initiatives were applied sequentially in Vietnam to } \\
\text { help reduce the extent of DWaP. These included (i) greater regulatory } \\
\text { enforcement, (ii) education among pharmacists especially regarding } \\
\text { uncomplicated acute respiratory infection (ARI) and (iii) peer influence } \\
\\
\text { - For ARI, antibiotic dispensing for ARI decreased appreciably following the } \\
\text { interventions compared with a control group of pharmacists. There were } \\
\text { also improvements in three other conditions analysed }\end{array}$ \\
\hline
\end{tabular}


There have been calls for the government in Saudi Arabia to enforce legislation banning DAwP in view of current concerns [93]. As a result in May 2018, a number of activities were instigated by the Saudi Ministry of Health to enforce the law and regulations prohibiting DAwP. Before, May 2018, the regulations were existed; however, they were not typically implemented and antibiotics were dispensed widely without a prescription and no legal actions were taken against those pharmacists who violated the law. However, in May 2018, the law was enforced and Ministry of Health through its official website and its other social media pages announced the enforcement of the law and that violators will face legal actions including imposing fines up to 100,000 SR (equivalent to US\$26,666) and cancellation of the licence in case of violations [94].

Whilst a number of studies have been undertaken across countries to analyse the impact of greater enforcement of regulations surrounding DAwP with varying success (Table 1), to the best of our knowledge, we believe no study has yet been conducted to evaluate the impact of this initiative in Saudi Arabia. We believe this is an important gap to address since an evaluation can inform health policy makers and the health regulators in Saudi Arabia and wider about the effectiveness of introduced measures including extensive fines to provide future guidance. In addition, such an analysis would help in providing a basis for discussing the need for any additional interventions in Saudi Arabia if required. Consequently, in this study we aimed to evaluate whether the activities of law enforcement and the potential for substantive fines had resulted in improved community pharmacists' behaviour and practice regarding DAwP in Saudi Arabia.

\section{Methods}

\subsection{Study design}

We adopted a pre- and post-law enforcement multi-methods study design [95]. The research project was conducted in two phases - before and after law enforcement and fines. Each phase consisted of two different methods, namely a cross-sectional questionnaire-based survey and a simulated client method (SCM).

This multi-method approach was adopted because the literature suggests that using tools that measure only self-reported practices could be prone to social desirability bias, which is the tendency of participants to choose socially acceptable responses rather than choosing responses that reflect their true feelings or practices [96]. In addition, the simulated client method is a well-recognized technique to reliably assess practices and behaviour including any malpractices in community pharmacies [19,23,24,40,97-99]. In the SCM, a three-steps design was implemented in the simulated patient scenarios to investigate the claim commonly reported in the literature that pharmacists dispense antibiotics without prescription because of the pressure exerted by patients $[20,66,74,100]$.

The pre-law enforcement phase of the study was conducted between December 2017 and March 2018, while the post-law enforcement phase was conducted a year later from December 2018 to March 2019 after the Saudi Ministry of Health (SMOH) imposed law enforcement in May 2018. The study scheme is presented in Figure 1. 
Figure 1: The design and flow of the study

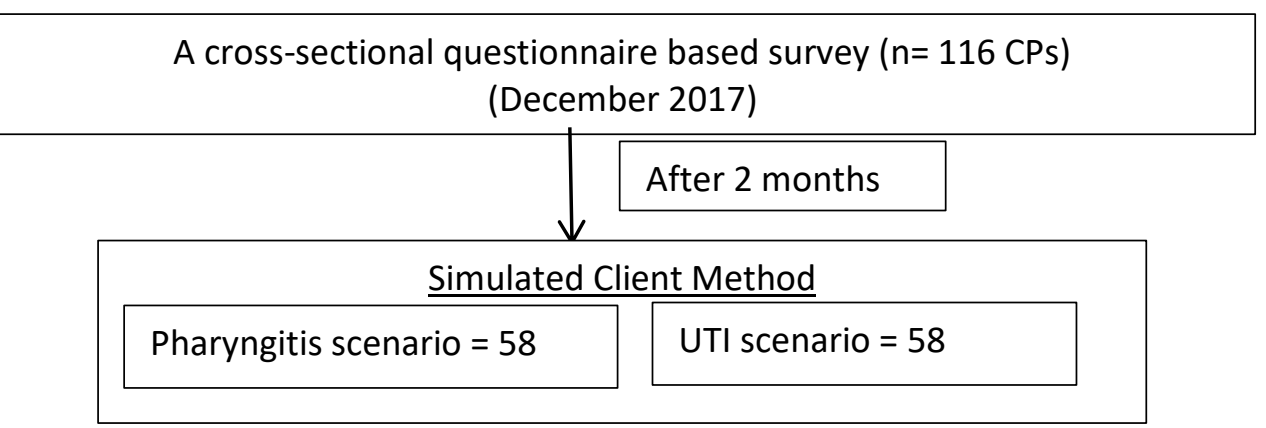

(December 2017-March 2018)

Law enforcement in May 2018

The questionnaire-based survey is repeated $(n=116 \mathrm{CPs})$

(December 2018)

$2^{\text {nd }}$ phase

(December 2018-March 2019)
After 2 months

Simulated Client Method is repeated

\begin{tabular}{l|l} 
Pharyngitis scenario $=58$ & UTI scenario $=58$
\end{tabular}

Pre- and post- law enforcement analysis and comparison

NB: $\mathrm{CPs}=$ community pharmacies; UTIs = urinary tract infections 


\subsection{Data collection}

The study used a structured, face and content validated, and pilot-tested questionnaire in the first part of each phase. The questionnaire was adopted from the literature, including the work of Hadi et al. (2016) [74]. The questionnaire was designed to elicit information on community pharmacists' knowledge, attitudes and practices regarding DAwP. Data collection was conducted twice in December 2017 ( $1^{\text {st }}$ phase before law enforcement) and December $2018\left(2^{\text {nd }}\right.$ phase after law enforcement). To administer the questionnaires, four data collectors were involved in the distribution of the questionnaires (two for each phase) and visiting the community pharmacies. During the visit to each pharmacy, data collectors sought permission from pharmacists after introducing themselves and explaining the purpose of the study before asking them to complete the questionnaires. These were self-administered questionnaires, and the role of data collectors was limited to the distribution of questionnaires. In addition, all the participants were assured that their responses would be treated confidentially and would only be used for research purposes.

In the second part of each phase, a simulated client Method (SCM) was adopted. The same community pharmacists who completed the questionnaires were visited again after two months from completing the questionnaire by two simulated patients other than those who delivered the questionnaires to them. Four simulated patients, who were pharmacy students, were trained to approach pharmacy staff, present clinical scenarios of either pharyngitis or urinary tract infections (UTI) in each community pharmacy since, as mentioned, they are the typical infections presenting to community pharmacists $[16,18-20,39,49,101]$. We have chosen the scenario of pharyngitis as the current literature suggests that it is common practice to dispense antibiotics for URTIs at community pharmacies in Saudi Arabia although this practice is not evidence-based as antibiotics are typically not needed in most URTIs, e.g. the study of Abdulhak et al (2011) showed that for URTIs antibiotics were dispensed in $90 \%$ of cases in Saudi Arabia [23,33,54,74]. In the second scenario, UTIs are also a common scenario used in literature. In addition, in this scenario the simulated patient was requesting a medication for his sister. This is because it is not uncommon in Saudi Arabia that a client is requesting medications for his/her relative and widely used in the literature from Saudi Arabia $[54,102]$ and elsewhere [99].

In the pharyngitis scenario, the simulated patient told the pharmacist that he has a fever and has difficulty swallowing since the past two days. In the UTI scenario, the simulated patient told the pharmacist that his 27 -year old sister (i.e. a childbearing age) is having dysuria and frequent urination. Only this clinical information was presented to the pharmacist. Any additional information was only provided if the pharmacist inquired about it (including the pregnancy status). The simulated patients used lay language and refrained from using any jargon.

Three sequential steps were followed before an antibiotic was dispensed or denied. First, the simulated patient asked for something to relieve the symptoms. Second, the simulated patient asked for something stronger if an antibiotic was not dispensed. In case an antibiotic was also denied, in the third step the simulated patient directly requested an antibiotic. In addition, if they were asked by the community pharmacists if they had other diseases or on other medications, the simulated patients would respond that they do not suffer from any other diseases and they do not take other medications. Moreover, the visits were made during the time it is possible to consult a physician either at a public or private clinic. To avoid forgetfulness, the investigators filled a standardized form including all obtained information immediately after leaving the pharmacy.

\subsection{Study population, sample size and Sampling technique}

The study population was community pharmacies in in Qassim region, Saudi Arabia. Qassim region consists of a capital city and 12 governorates with a total population of approximately 1.46 million [103,104]. In total, there were 422 community pharmacies in Qassim Region in 2017 [105]. However, since no up-to-date list of community pharmacies with full addresses was available to the research team at the time the study was conducted, a convenient sampling approach was adopted. To maximize sample diversity, enhance the generalizability of the findings, and minimize selection bias, the research team chose governorates based on population density. Consequently, the governorates were divided into zones (i.e. North, South, East and West), and the zones were further sub-divided into districts. The community pharmacies were selected from these districts using convenience sampling procedures, i.e. chosen based on practical criteria including geographical proximity, 
availability at the time of first visit, and easy accessibility. In this study, five main cities/governorates were finally chosen namely, Buraidah, Unaizah, Arras, Badaya and Albukairyah.

Taking into consideration the feasibility and logistical issue as the study design requires simulated patients to visit each pharmacy four times over a one-year period (two visits in each phase for questionnaire administration and SCM), a quarter of all pharmacies in the region $(n=116 ; 27.5 \%)$ were targeted and included in the study. No pharmacist refused to complete the questionnaire giving a $100 \%$ response rate to their inclusion in the study. In each phase, the 116 pharmacies were visited for questionnaire administration. Similarly, in the SCM, all the 116 pharmacies were visited for one scenario, i.e. 58 visits for the pharyngitis scenarios and 58 visits for UTI. Each community pharmacy was visited for the same scenario in both phases.

\subsection{Data analysis}

Descriptive statistics such as frequency and percentages were used to summarize the data. The inferential statistics included the Chi square test ( $x^{2}$ test), and Fisher's exact test when appropriate. The significance level was set at $P$ value less than 0.05 . Statistical analyses were performed using the Statistical Package for Social Sciences (SPSS) version 22.0 for Windows.

\subsection{Study approval}

The study protocol was reviewed and approved by the Scientific Research Committee at Unaizah College of Pharmacy, Qassim University, Saudi Arabia.

\section{Results}

\subsection{The practice of DAwP}

In the cross-sectional questionnaire-based survey, before the law enforcement, $70.7 \%$ of participating pharmacies believed that DAwP is common among them in Saudi Arabia. In the SCM, $96.6 \%$, and $87.7 \%$ of participants dispensed antibiotics without prescriptions for pharyngitis and UTI scenarios, respectively. After law enforcement, only $12.9 \%$ believed that DAwP is a common practice. This is confirmed by the SCM with only $12.1 \%$ and $5.2 \%$ of the visited pharmacies dispensing antibiotics without prescriptions for the pharyngitis and UTI scenarios, respectively. The comparison is presented in Figure 2 and all the details are summarized in Tables 2 and 3.

\section{Figure 2: The practice of DAwP before and after the law enforcement}

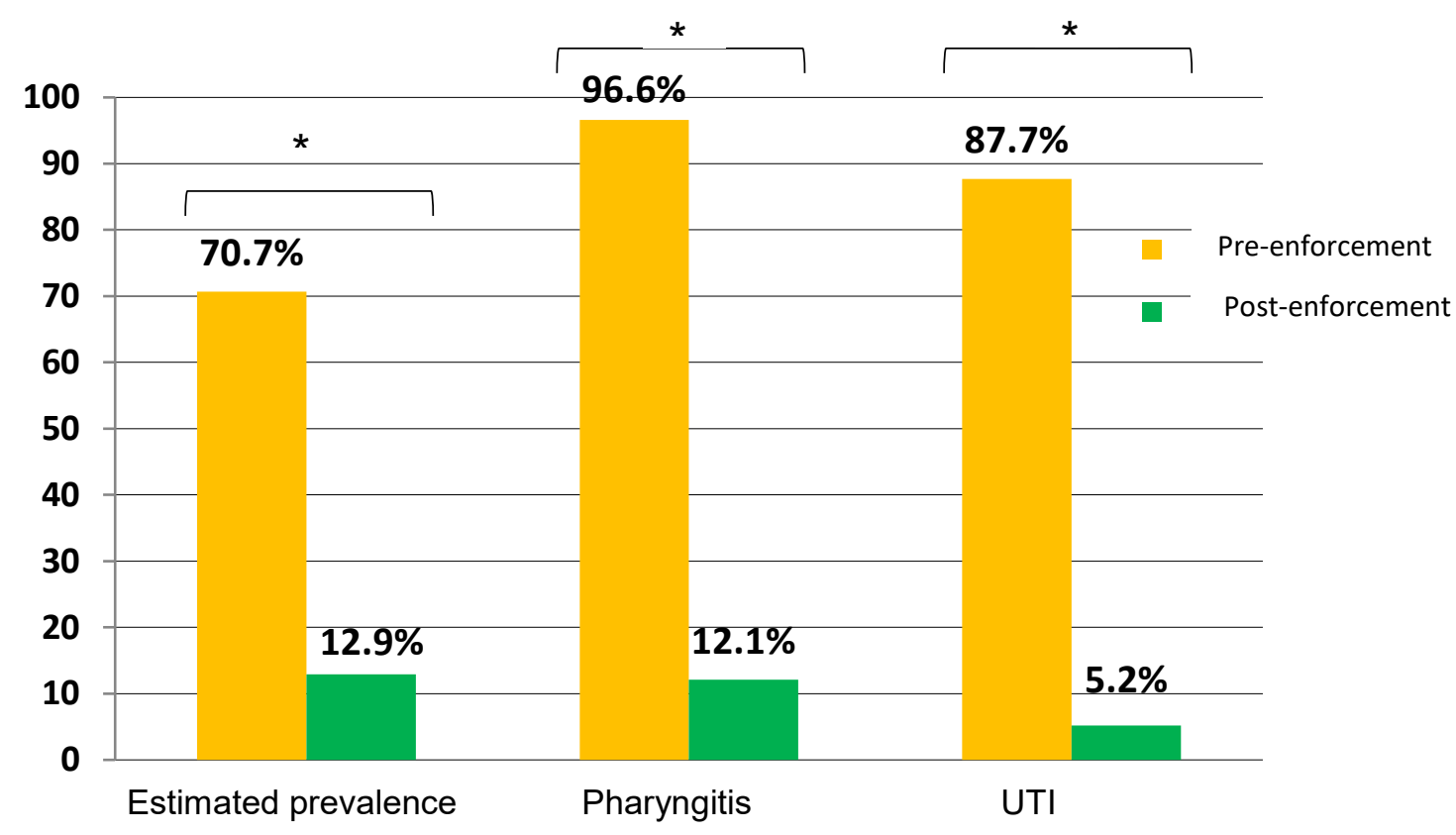

NB: * indicates statistically significant at $P<0.001$. 


\subsection{Knowledge and perceptions towards DAwP}

In this study, there were only few statistically significant differences in terms of community pharmacists' knowledge and perceptions towards DAwP before and after law enforcement.

In fact, the majority of participants were aware that DAwP is illegal in Saudi Arabia (89.7\% and $96.6 \%$, pre- and post- law enforcement, respectively $P=0.179)$. Moreover, most participants stated that DAwP is contributing to the development of AMR (91.4\% and 93.1\%, pre- and post- law enforcement, respectively $\mathrm{P}=0.242$ ). Similarly, the majority of community pharmacists believed that AMR has become a public health issue $(87.9 \%$ and 87.1 pre- and post- law enforcement, respectively $\mathrm{P}=$ $0.898)$. Consequently, the majority believed that pharmacists should stop DAwP $(82.8 \%$ and $82.8 \%$ pre- and post- law enforcement, respectively $\mathrm{P}=0.99$ ). However, after law enforcement, many pharmacists still had the feeling that if an antibiotic is not dispensed, patients will try to obtain it from another pharmacy. Similarly, many pharmacists reported that refusing DAwP will negatively affect their sales and profits $(56.0 \%$ and $53.4 \%$ pre- and post- law enforcement, respectively $P=0.99)$. The results are presented in Table 2.

Table 2 Community pharmacists' Knowledge and perceptions towards DAwP*

\begin{tabular}{|c|c|c|c|c|c|}
\hline Variable & & $\begin{array}{l}\text { Yes } \\
\mathrm{n}(\%)\end{array}$ & $\begin{array}{c}\text { No } \\
\mathrm{n}(\%)\end{array}$ & $\begin{array}{c}\text { Don't know } \\
\mathrm{n}(\%)\end{array}$ & $p$-value \\
\hline \multirow[b]{2}{*}{ DAwP is legal in Saudi Arabia } & Before & $8(6.9)$ & $104(89.7)$ & $2(1.7)$ & \multirow[b]{2}{*}{0.179} \\
\hline & After & $2(1.7)$ & $112(96.6)$ & $2(1.7)$ & \\
\hline \multirow[t]{2}{*}{$\begin{array}{l}\text { DAwP is common among community } \\
\text { pharmacists in Saudi Arabia }\end{array}$} & Before & $82(70.7)$ & $20(17.2)$ & $14(12.1)$ & \multirow{2}{*}{$<0.001$} \\
\hline & After & $15(12.9)$ & $92(79.3)$ & $8(6.9)$ & \\
\hline \multirow[t]{2}{*}{$\begin{array}{l}\text { Do you think there is any problem if you } \\
\text { dispense medication without prescription }\end{array}$} & Before & $102(87.9)$ & $14(12.1)$ & $0(0.0)$ & \multirow{2}{*}{$0.033^{*}$} \\
\hline & After & $89(76.7)$ & $25(21.6)$ & $2(1.7)$ & \\
\hline \multirow{2}{*}{$\begin{array}{l}\text { DAwP is contributing to the development } \\
\text { of antimicrobial resistance }\end{array}$} & Before & $106(91.4)$ & $8(6.9)$ & $1(0.9)$ & \multirow{2}{*}{0.242} \\
\hline & After & $108(93.1)$ & $4(3.4)$ & $4(3.4)$ & \\
\hline \multirow{2}{*}{$\begin{array}{l}\text { Antibiotic resistance has become a public } \\
\text { health issue }\end{array}$} & Before & $102(87.9)$ & $9(7.8)$ & $3(2.6)$ & \multirow{2}{*}{0.898} \\
\hline & After & $101(87.1)$ & $11(9.5)$ & $4(3.4)$ & \\
\hline \multirow[t]{2}{*}{$\begin{array}{l}\text { DAwP is contributing to the inappropriate } \\
\text { use of antibiotics by patients }\end{array}$} & Before & $101(87.1)$ & $11(9.5)$ & $4(3.4)$ & \multirow{2}{*}{0.93} \\
\hline & After & $98(84.5)$ & $11(9.5)$ & $5(4.3)$ & \\
\hline \multirow[t]{2}{*}{ Pharmacists should stop DAwP } & Before & $96(82.8)$ & $18(15.5)$ & $2(1.7)$ & \multirow{2}{*}{0.99} \\
\hline & After & $96(82.8)$ & $17(14.7)$ & $3(2.6)$ & \\
\hline \multirow[t]{2}{*}{$\begin{array}{l}\text { I encourage patients to consult the } \\
\text { physician and get a prescription }\end{array}$} & Before & $114(98.3)$ & $2(1.7)$ & $0(0.0)$ & \multirow{2}{*}{0.102} \\
\hline & After & $108(93.1)$ & $8(6.9)$ & $0(0.0)$ & \\
\hline \multirow{2}{*}{$\begin{array}{l}\text { When patients feel that they need an } \\
\text { antibiotic, if not dispensed, they will try to } \\
\text { obtain it from another pharmacy }\end{array}$} & Before & $107(92.3)$ & $2(1.7)$ & $7(6.0)$ & \multirow{2}{*}{$<0.001^{*}$} \\
\hline & After & $78(67.2)$ & $12(10.3)$ & $26(22.4)$ & \\
\hline \multirow[t]{2}{*}{$\begin{array}{l}\text { Refusing DAwP will negatively affect } \\
\text { sales and profits }\end{array}$} & Before & $65(56.0)$ & $46(39.7)$ & $5(4.3)$ & \multirow{2}{*}{0.99} \\
\hline & After & 64 (53.4) & $47(40.5)$ & $5(4.3)$ & \\
\hline
\end{tabular}

NB = DAwP = dispensing antibiotics without prescription * not all variables add up to 116 due to missing data 


\subsection{Patient education and counselling about antibiotics}

Regarding patient education and counselling about the importance of adherence and appropriate use of antibiotics, the SCM revealed that in the cases where DAwP was practiced in the post-law enforcement period, there was a major improvement in counselling and education compared to the pre-enforcement phase. In fact, $85.7 \%$ and $100 \%$ of the simulated patients received counselling and education in the post-law enforcement for the pharyngitis and UTI scenarios, respectively, compared to only $50 \%$ and $52 \%$ in the pre-law enforcement phase. Moreover, the results showed a major difference in the step in which the antibiotic was dispensed. Before law enforcement, this was mainly in the $1^{\text {st }}$ step (i.e. $85.7 \%$ and $74 \%$ for pharyngitis and UTI, respectively) while the opposite occurred after the enforcement as DAwP mostly occurred after the patients insisted in Step $3(57.1 \%$ and $66.7 \%$ for pharyngitis and UTI, respectively in Step 3).

In addition, while the reason behind refusing dispensing antibiotic without prescription was a 'healthrelated reason' in the majority of cases in the pre-law enforcement simulated patient survey, the contrary was true in the post-law enforcement simulated patient survey with the majority stating a 'regulations-related reason'. Details of the results of a comparison between pre and post-law enforcement simulated patient survey concerning community pharmacists' behaviours while practicing DAwP are presented in Table 3.

Table 3: Community pharmacists' behaviour while practicing DAwP (58 visits for each scenario at each point of time before and after law enforcement)

\begin{tabular}{|c|c|c|c|c|}
\hline \multirow[t]{2}{*}{ Item } & \multicolumn{2}{|c|}{ Pharyngitis scenario } & \multicolumn{2}{|c|}{ UTI scenario } \\
\hline & Before N (\%) & After N (\%) & Before N (\%) & After N (\%) \\
\hline Dispensed antibiotic without prescription & $56(96.6)$ & $7(12.1)^{* *}$ & $50(87.7)$ & $3(5.2)^{* *}$ \\
\hline $\begin{array}{l}\text { Educated about the importance of adherence } \\
\text { and completion of antibiotic course }\end{array}$ & $28(50.0)$ & $6(85.7)$ & $26(52.0)$ & $3(100.0)$ \\
\hline \multicolumn{5}{|l|}{ Step in which antibiotic was dispenseda } \\
\hline $1^{\text {st }}$ step & $48(85.7)$ & $1(14.3)$ & $37(74.0)$ & $1(33.3)$ \\
\hline $2^{\text {nd }}$ step & $3(5.4)$ & $2(28.6)$ & $4(8.0)$ & $0(0)$ \\
\hline $3^{\text {rd }}$ step & $5(8.9)$ & $4(57.1)$ & $9(18.0)$ & $2(66.7)$ \\
\hline \multicolumn{5}{|l|}{$\begin{array}{l}\text { Reason behind refusing dispensing antibiotic } \\
\text { without prescription }\end{array}$} \\
\hline Health-related reason & $2(100)$ & $2(4.0)$ & $5(71.4)$ & $5(9.1)$ \\
\hline Regulations-related reason & $0(0)$ & $49(96.0)$ & $2(28.6)$ & $50(90.9)$ \\
\hline
\end{tabular}

\section{Discussion}

We believe this is the first study in Saudi Arabia that has evaluated the impact of the regulatory intervention to enforce the laws prohibiting DAwP. The study findings showed that enforcement of the law coupled with substantial fines resulted in a significant decrease in the prevalence of DAwP. It was reduced significantly by more than $80 \%$ after law enforcement and fines (Figure 2, Table 3).

This reduction would appear to be greater than the significant reductions in DAwP seen in Chile, Mexico, and the Republic of Srpska, following greater enforcement of the laws and appreciably greater than seen with the combined studies in Brazil, Colombia and Venezuela (Table 1). This reduction in Saudi Arabia may have been helped by the level of potential fines coupled with the explanation for denying an antibiotic without a prescription. Unlike during the pre-law enforcement phase, DAwP only happened post phase after considerable pressure from patients (Step 3 - Table 3 ). In addition, when an antibiotic was denied in the post-law enforcement phase, the reason was mostly regulations-related, while it was mostly 'health-related' in the few cases antibiotics denied in the pre- 
law enforcement phase. As a result, changing patients' expectations which is important given the pressure that patients or parents can place on pharmacists to dispense an antibiotic without a prescription in a number of countries $[20,49,66,74,100]$. After law enforcement, patient counselling and education about antibiotics also increased when antibiotics were dispensed without prescription (Table 3). This is encouraging as there are a number of key issues that need to be discussed with patients when dispensing antibiotics including allergies, dosing and the need to complete the full course $[34,73,74,76]$. These findings in Saudi Arabia compare very favourably with a recent study in UAE where only $1.4 \%$ of the patients were given instructions on how to use antibiotics and none were informed of their potential side effects [106].

Of interest is that there appeared to be no significant changes in the knowledge and perceptions of community pharmacists between pre- and post-law enforcement on many aspects related to DAwP (Table 2). These included their awareness of the existing law prohibiting dispensing antibiotics without prescription, the negative impact of DAwP and the associated issues with antimicrobial resistance. This may reflect ongoing programmes within the universities to improve pharmacists' knowledge regarding antibiotics, AMR and the regulations surrounding DAwP. This is in line with national action plan of Saudi Arabia on combating AMR. Objective two of this plan stated that AMR and related topics should be emphasized in the professional programs of health colleges including Pharmacy Colleges [107]. In addition, several awareness programs are currently being conducted by Pharmacy colleges in Saudi Arabia targeting both healthcare professionals and the general public regarding the rational use of antibiotics [108]. However, still a large proportion of pharmacists believed that patients would seek antibiotics from other community pharmacies if not dispensed, which is a continuing concern. This again highlights the importance that interventions, such as law enforcement, should be accompanied by strategies that raise awareness about, and promote appropriate use, of antibiotics among all key stakeholders including healthcare professionals and patients $[12,13,70,77,109]$.

Our findings indicate the need to introduce additional measures and interventions in Saudi Arabia targeting all key stakeholders including physicians, patients and the general public to further enhance the appropriate use of antibiotics. This can be undertaken via public awareness campaigns, patients' materials and other interventions in a more holistic approach given some of the findings seen in other countries and the need to sustain current low levels of DAwP in Saudi Arabia (Table 1). These are of great importance as the current evidence derived from the studies utilizing theory of planned behaviour to investigate predictors of intention to dispense antibiotics by community pharmacists suggests that attitudes towards antibiotics in terms of their benefit and harms had strong influence on pharmacists' intention to dispense antibiotics. In addition, subjective norms including pressure from patients and easy access to antibiotics from other pharmacies do influence pharmacists' practice $[20,33,110,111]$. In addition, some community pharmacists in this study still believed there is no problem if antibiotics are dispensed without a prescription. This is in line with the findings of Amin et al. 2017 from Egypt in which some community pharmacists believed there is no problem in dispensing antibiotics without a prescription, i.e. they assumed the 'non-malfeasance' principle is not violated [110]. These are important findings and need to be considered during educational and other interventions to ensure the sustainability of any intervention. We will be monitoring such developments in the future.

Currently, pharmacists in Saudi Arabia are not authorized legally to dispense antibiotics without a prescription for all conditions. However, some arguments are raised regarding this legal limitation and strict limitation might not be the best option. It is being argued that dispensing antibiotics for some specific clinical situations could be supported especially in conditions that can be identified by simply interviewing the patient without the need to perform clinical exams. For example, in the UK, pharmacists can legally dispense azithromycin to patients with positive chlamydia test results and in New Zealand, pharmacists can supply trimethoprim for short-term treatment of an uncomplicated UTI [16]. However, to consider this in Saudi Arabia there needs to be considerable training of community pharmacists on antimicrobial stewardship programs to ensure appropriate use of antibiotics for these clinical situations. Moreover, it should further investigated whether such a step is necessary in terms of accessibility to antibiotics especially if access to primary care physicians is widely available via a large number of primary care centers and medical polyclinics, which is unlike the situation in the UK where there can be extensive waiting times to see general practitioners [112]. In 2017 in Saudi Arabia, there were 2393 primary healthcare centers (public sector) and 1338 medical polyclinics (Private sector) for a population of approximately 34.5 million [105]. 
The study has several implications. It demonstrates that enforcement of the law coupled with strong measures such as fines and potential closure of pharmacies can have an appreciable impact on DAwP. This compares with situations where there is limited enforcement of the law. Other measures though are also needed to improve future prescribing and dispensing of antibiotics to address the many reasons for continued abuse of antibiotics. These include education among patients and the public especially that taking antibiotics for viral infections such as colds and sore throats will not speed up recovery and may lead to side-effects and the build-up of resistance. In addition, continued education among physicians about antibiotics and AMR coupled with monitoring of their prescribing and possible incentives to reduce inappropriate antibiotic prescribing as well as education and guidance for community pharmacists. Community pharmacists are especially important as often they are the first healthcare professional that patients consult with regarding conditions such as colds, sore throats and UTIs $[30,40,113]$. This is critical in lower and middle income countries. Consequently, targeting DAwP is essential across many countries especially LMICs given the influence this has on enhancing inappropriate antibiotic utilisation especially in self-limiting conditions. To date, there have only been a limited number of studies that have demonstrated the influence of different measures to reduce DAwP. This study in Saudi Arabia adds to the knowledge base, and is especially important for countries in the Middle East where this practice has been prevalent despite being illegal.

\section{Strengths and Limitations}

The study had a number of strengths. The study adopted a multi- methods design to assess real practice by employing a non-traditional method (i.e. a simulated client method). Moreover, the study targeted community pharmacies from five different cities of the region. However, there are some limitations in the study. Firstly, we employed a convenience sampling method to collect the data. However, this was inevitable due to several logistical and practical barriers. Secondly, the study included only 116 pharmacies. However, given the complexity of the design, i.e. the need to visit each community pharmacy four times over one year by different data collectors, a larger sample size was not feasible. The study was also only conducted in one administrative region of Saudi Arabia, i.e. Qassim region, again due to logistical and practical barriers. Consequently, the findings might not be generalizable to the other 12 administrative regions of the country. In addition, whilst the same pharmacies were visited in both phases of the study, this might not necessarily be the same pharmacist since in some community pharmacies there were more than one pharmacist working in the same pharmacy. However, we believe it is the same practice adopted at the level of the pharmacy. However, despite these limitations, we believe the study finding are robust and provide future guidance to the health authorities in Saudi Arabia and wider.

\section{Conclusion and Recommendations}

We believe the study findings show that law enforcement including the potential for substantial fines and loss of the licence to practice are effective in reducing DAwP. The prevalence of DAwP was significantly decreased by more than $80 \%$ after law enforcement.

However, we believe there is still further scope for improvement. This includes greater educational activities among all key stakeholder groups including patients to reduce expectations of being prescribed or dispensed an antibiotic for essentially self-limiting conditions. This is particularly important as restricting access to the over-the-counter antibiotics is only one component among many to enhance the future rational use of antibiotics and reduce AMR rates.

\section{Key issues/ Highlights}

- There was considerable dispensing of antibiotics among community pharmacists in Saudi Arabia despite legislation banning this

- In May 2018, greater enforcement of the dispensing of antibiotics without a prescription (DAwP) took place with imposing of fines up to 100,000 SR (equivalent to US $\$ 26,666$ ) and cancellation of the licence in case of violations

- This resulted in a considerable reduction on DAwP with only $12.9 \%$ of community pharmacists reporting that DAwP is still a common practice, with only $12.1 \%$ and $5.2 \%$ of pharmacists dispensing antibiotics without prescriptions for pharyngitis and UTI respectively; with this typically only occurring following specific requests

- However, there is still a need for greater educational activities among all key stakeholder groups including patients to reduce expectations of being prescribed or dispensed an antibiotic for essentially self-limiting conditions 
- Multiple activities are in line with the goals of the national action plan of Saudi Arabia on combating AMR

\section{Funding}

Nil

\section{Conflicts of interest}

The authors declare they have no conflicts of interest

\section{References}

("of interest, ${ }^{* *}$ of considerable interest)

1. Goossens $\mathrm{H}$. Antibiotic consumption and link to resistance. Clinical microbiology and infection. 2009;15 Suppl 3:12-5.

2. Jinks $T$, Lee $N$, Sharland $M$ et al. A time for action: antimicrobial resistance needs global response. Bull World Health Organ. 2016;94(8):558-a.

3. Bell BG, Schellevis F, Stobberingh E et al. A systematic review and meta-analysis of the effects of antibiotic consumption on antibiotic resistance. BMC Infectious Diseases. 2014;14:13-.

4. Michael CA, Dominey-Howes D, Labbate M. The antimicrobial resistance crisis: causes, consequences, and management. Front Public Health. 2014;2:145.

5. Cassini A, Hogberg LD, Plachouras D et al. Attributable deaths and disability-adjusted lifeyears caused by infections with antibiotic-resistant bacteria in the EU and the European Economic Area in 2015: a population-level modelling analysis. The Lancet Infectious diseases. 2019;19(1):5666.

6. Hofer U. The cost of antimicrobial resistance. Nature reviews Microbiology. 2019;17(1):3. ${ }^{*}$ Good review of the current costs of AMR

7. O'Neill J. Antimicrobial Resistance: Tackling a crisis for the health and wealth of nations. The Review on Antimicrobial Resistance. 2014. Available at URL: https://amr-

review.org/sites/default/files/AMR\%20Review\%20Paper\%20-

\%20Tackling\%20a\%20crisis\%20for\%20the \%20health\%20and\%20wealth\%20of\%20nations_1.pdf.

8. Founou RC, Founou LL, Essack SY. Clinical and economic impact of antibiotic resistance in developing countries: A systematic review and meta-analysis. PloS one. 2017;12(12):e0189621.

9. WHO. World Health Assembly addresses antimicrobial resistance, immunization gaps and malnutrition. Available at UTL: http://www.who.int/mediacentre/news/releases/2015/wha-25-may2015/en/

10. WHO. Antibiotic resistance: multi-country public awareness survey. 2015. Available at URL: http://apps.who.int/iris/bitstream/handle/10665/194460/9789241509817_eng.pdf;jsessionid=8DF6DD5 5B7784166CDC6B1F4A17273A0?sequence=1.

11. Schellack N, Benjamin D, Brink A et al. A situational analysis of current antimicrobial governance, regulation, and utilization in South Africa. International journal of infectious diseases. 2017;64:100-6.

12. Furst J, Cizman M, Mrak J et al. The influence of a sustained multifaceted approach to improve antibiotic prescribing in Slovenia during the past decade: findings and implications. Expert review of anti-infective therapy. 2015;13(2):279-89.

13. Abilova V, Kurdi A, Godman B. Ongoing initiatives in Azerbaijan to improve the use of antibiotics; findings and implications. Expert review of anti-infective therapy. 2018;16(1):77-84. 14. Saleem Z, Hassali MA, Hashmi FK. Pakistan's national action plan for antimicrobial resistance: translating ideas into reality. The Lancet Infectious diseases. 2018;18(10):1066-7. 15. Essack SY, Desta AT, Abotsi RE et al. Antimicrobial resistance in the WHO African region: current status and roadmap for action. Journal of public health. 2017;39(1):8-13.

16. Auta A, Hadi MA, Oga E, Adewuyi EO, Abdu-Aguye SN, Adeloye D, et al. Global access to antibiotics without prescription in community pharmacies: A systematic review and meta-analysis. The Journal of infection. 2019;78(1):8-18.

${ }^{*}$ Good summary of the extent of self-purchasing of antibiotics worldwide

17. Nepal G, Bhatta S. Self-medication with Antibiotics in WHO Southeast Asian Region: A Systematic Review. Cureus. 2018;10(4):e2428.

18. Ocan M, Obuku EA, Bwanga Fet al. Household antimicrobial self-medication: a systematic review and meta-analysis of the burden, risk factors and outcomes in developing countries. BMC public health. 2015;15:742. 
19. Sakeena MHF, Bennett AA, McLachlan AJ. Non-prescription sales of antimicrobial agents at community pharmacies in developing countries: a systematic review. International journal of antimicrobial agents. 2018;52(6):771-82.

20. Torres NF, Chibi B, Middleton LE et al. Evidence of factors influencing self-medication with antibiotics in low and middle-income countries: a systematic scoping review. Public health. 2019;168:92-101.

${ }^{* *}$ Interesting review paper discussing key factors influencing the self-purchasing of antibiotics 21. Alhomoud F, Aljamea Z, Almahasnah R et al. Self-medication and self-prescription with antibiotics in the Middle East-do they really happen? A systematic review of the prevalence, possible reasons, and outcomes. International journal of infectious diseases. 2017;57:3-12.

22. Erku DA, Aberra SY. Non-prescribed sale of antibiotics for acute childhood diarrhea and upper respiratory tract infection in community pharmacies: a 2 phase mixed-methods study. Antimicrob Resist Infect Control. 2018;7:92.

23. Chang J, Xu S, Zhu S et al. Assessment of non-prescription antibiotic dispensing at community pharmacies in China with simulated clients: a mixed cross-sectional and longitudinal study. Lancet Infect Dis. 2019;19(12):1345-1354

24. Kalungia A, Godman B. Implications of non-prescription antibiotic sales in China. The Lancet Infectious diseases. 2019;19(12):1272-3.

25. Plachouras D, Kavatha D, Antoniadou A et al. Dispensing of antibiotics without prescription in Greece, 2008: another link in the antibiotic resistance chain. Euro surveillance. 2010;15(7).

26. Morgan DJ, Okeke IN, Laxminarayan R et al. Non-prescription antimicrobial use worldwide: a systematic review. The Lancet Infectious diseases. 2011;11(9):692-701.

27. Awad A, Eltayeb I, Matowe $L$ et al. Self-medication with antibiotics and antimalarials in the community of Khartoum State, Sudan. J Pharm Pharm Sci. 2005;8.

28. Hadi U, Duerink DO, Lestari ES et al. Survey of antibiotic use of individuals visiting public healthcare facilities in Indonesia. International Journal of Infectious Diseases. 2008;12(6):622-9.

29. FIP. FIP statement of policy - control of antimicrobial medicines resistance (AMR). Available from URL: http://www.fip.org/www/uploads/database_file.php?id=289\&table_id

30. WHO. The role of pharmacist in encouraging prudent use of antibiotics and averting antimicrobial resistance: a review of policy and experience. Available at URL:

http://www.euro.who.int/_data/assets/pdf_file/0006/262815/The-role-of-pharmacist-in-encouragingprudent-use-of-antibiotics-and-averting-antimicrobial-resistance-a-review-of-policy-and-experienceEng.pdf?ua=1 [

31. Cameron A, Ewen M, Ross-Degnan D et al. Medicine prices, availability, and affordability in 36 developing and middle-income countries: a secondary analysis. Lancet. 2009;373(9659):240-9.

32. Aregbeshola BS, Khan SM. Out-of-Pocket Payments, Catastrophic Health Expenditure and Poverty Among Households in Nigeria 2010. International journal of health policy and management. 2018;7(9):798-806.

33. Godman B, Haque M, McKimm J et al. Ongoing strategies to improve the management of upper respiratory tract infections and reduce inappropriate antibiotic use particularly among lower and middle-income countries: findings and implications for the future. Current medical research and opinion. 2019:1.

${ }^{*}$ Comprehensive summary of ongoing initiatives especially in LMICs to reduce the use of antibiotics for URTIs

34. Kalungia AC, Burger J, Godman B et al. Non-prescription sale and dispensing of antibiotics in community pharmacies in Zambia. Expert review of anti-infective therapy. 2016;14(12):1215-23.

35. Machowska A, Stålsby Lundborg C. Drivers of Irrational Use of Antibiotics in Europe.

International journal of environmental research and public health. 2018;16(1):27.

36. Van Boeckel TP, Gandra S, Ashok A et al. Global antibiotic consumption 2000 to 2010: an analysis of national pharmaceutical sales data. The Lancet Infectious diseases. 2014;14(8):742-50.

37. Klein EY, Van Boeckel TP, Martinez EM et al. Global increase and geographic convergence in antibiotic consumption between 2000 and 2015. Proceedings of the National Academy of Sciences of the United States of America. 2018;115(15):E3463-e70.

38. Almaaytah A, Mukattash TL, Hajaj J. Dispensing of non-prescribed antibiotics in Jordan. Patient preference and adherence. 2015;9:1389-95.

39. Haddadin RN, Alsous M, Wazaify M et al. Evaluation of antibiotic dispensing practice in community pharmacies in Jordan: A cross sectional study. PloS one. 2019;14(4):e0216115-e.

40. Markovic-Pekovic V, Grubisa N, Burger J et al. Initiatives to Reduce Nonprescription Sales and Dispensing of Antibiotics: Findings and Implications. J Res Pharm Pract. 2017;6(2):120-5. 
*Summary of ongoing initiatives among pharmacists to improve their management of patients in the community including respiratory infections

41. Zapata-Cachafeiro M, González-González C, Váquez-Lago JMet al. Determinants of antibiotic dispensing without a medical prescription: a cross-sectional study in the north of Spain. Journal of Antimicrobial Chemotherapy. 2014;69(11):3156-60.

42. Grigoryan L, Monnet DL, Haaijer-Ruskamp FM et al. Self-medication with antibiotics in Europe: a case for action. Current drug safety. 2010;5(4):329-32.

43. Lescure D, Paget J, Schellevis F et al. Determinants of Self-Medication With Antibiotics in European and Anglo-Saxon Countries: A Systematic Review of the Literature. Front Public Health. 2018;6:370.

44. Abdelaziz Al, Tawfik AG, Rabie KA et al. Quality of Community Pharmacy Practice in Antibiotic Self-Medication Encounters: A Simulated Patient Study in Upper Egypt. Antibiotics. 2019;8(2):35.

45. Abuirmeileh A, Samara S, Alkhodari A et al. Antibiotic dispensing without prescription in Jordanian community pharmacies: a pharmacist's perspective. Bulletin of Pharmaceutical Sciences. 2014;37:51-63.

46. Al-Faham Z, Habboub G, Takriti F. The sale of antibiotics without prescription in pharmacies in Damascus, Syria. Journal of infection in developing countries. 2011;5(5):396-9.

47. Helal R, Abou-EIWafa H. Self-medication in university students from the city of Mansoura, Egypt. Journal of environmental and public health. 2017;2017.

48. Sabry NA, Farid SF, Dawoud DM. Antibiotic dispensing in Egyptian community pharmacies: an observational study. Research in social \& administrative pharmacy. 2014;10(1):168-84.

49. Bahnassi A. A qualitative analysis of pharmacists' attitudes and practices regarding the sale of antibiotics without prescription in Syria. Journal of Taibah University Medical Sciences.

2015;10(2):227-33.

50. Mikhael EM. Evaluating the rationality of antibiotic dispensing in treating common cold infections among pharmacists in Baghdad, Iraq. Br J Pharm Res 2014; 4: 2653-2661.

51. Jasim AL, Fadhil TA, Taher SS: Self-medication practice among Iraqi patients in Baghdad city. Am J Pharmacol Sci. 2014; 2:18-23.

52. Alrasheedy AA, Hassali MA, Wong ZY et al. Pharmaceutical policy in Saudi Arabia.

Pharmaceutical Policy in Countries with Developing Healthcare Systems: Springer; 2017. p. 329-47.

53. Khan TM. The consequences of nonprescription medication sales in Saudi Arabia's

community pharmacies: regulations without implementation. Therapeutic advances in drug safety. 2014;5(4):173-4.

54. Abdulhak AAB, Al Tannir MA, Almansor MAet al. Non prescribed sale of antibiotics in Riyadh, Saudi Arabia: a cross sectional study. BMC public health. 2011;11(1):538.

55. Al-Freihi H, Ballal SG, Jaccarini A et al. Potential for drug misuse in the eastern province of Saudi Arabia. Annals of Saudi Medicine. 1987;7(4):301-5.

56. Al-Ghamdi MS. Empirical treatment of uncomplicated urinary tract infection by community pharmacist in the Eastern province of Saudi Arabia. Saudi medical journal. 2001;22(12):1105-8.

57. Al-Mohamadi A, Badr A, Bin Mahfouz $L$ et al. Dispensing medications without prescription at Saudi community pharmacy: Extent and perception. Saudi Pharmaceutical Journal. 2013;21(1):13-8.

58. Bawazir S. Prescribing pattern at community pharmacies in Saudi Arabia. International Pharmacy Journal. 1992;6:222-.

59. Khan TM, Ibrahim Y. A qualitative exploration of the non-prescription sale of drugs and incidence of adverse events in community pharmacy settings in the Eastern Province of the Kingdom of Saudi Arabia. European Journal of Hospital Pharmacy: Science and Practice. 2013;20(1):26-31.

60. Nafisah SB, Nafesa SB, Alamery AH, Alhumaid MA, AlMuhaidib HM, Al-Eidan FA. Over-thecounter antibiotics in Saudi Arabia, an urgent call for policy makers. Journal of infection and public health. 2017;10(5):522-6.

61. Emeka PM, Al-Omar M, Khan TM. Public attitude and justification to purchase antibiotics in the Eastern region Al Ahsa of Saudi Arabia. Saudi pharmaceutical journal. 2014;22(6):550-4.

62. Alshammari TM, Alhindi SA, Alrashdi AM et al. Pharmacy Malpractice: The rate and prevalence of dispensing high-risk prescription-only medications at community pharmacies in Saudi Arabia. Saudi pharmaceutical journal. 2017;25(5):709-14.

63. Rather IA, Kim BC, Bajpai VK et al. Self-medication and antibiotic resistance: Crisis, current challenges, and prevention. Saudi journal of biological sciences. 2017;24(4):808-12.

64. Hoxha I, Malaj A, Kraja B et al. Are pharmacists' good knowledge and awareness on antibiotics taken for granted? The situation in Albania and future implications across countries. Journal of global antimicrobial resistance. 2018;13:240-5. 
*Interesting paper highlighting concerns with knowledge of antibiotics and AMR among pharmacists 65. Saradamma RD, Higginbotham N, Nichter M. Social factors influencing the acquisition of antibiotics without prescription in Kerala State, south India. Soc Sci Med. 2000;50(6):891-903.

66. Akinyandenu $\mathrm{O}$, Akinyandenu A. Irrational use and non-prescription sale of antibiotics in Nigeria, a need for change. J Sci Innov Res. 2014;3(2):251-7.

67. Farah R, Lahoud N, Salameh $\mathrm{P}$ et al. Antibiotic dispensation by Lebanese pharmacists: a comparison of higher and lower socio-economic levels. Journal of infection and public health. 2015;8(1):37-46.

68. Mbonye AK, Buregyeya E, Rutebemberwa E et al. Prescription for antibiotics at drug shops and strategies to improve quality of care and patient safety: a cross-sectional survey in the private sector in Uganda. BMJ open. 2016;6(3):e010632.

69. Servia-Dopazo M, Figueiras A. Determinants of antibiotic dispensing without prescription: a systematic review. The Journal of antimicrobial chemotherapy. 2018;73(12):3244-53.

70. Bojanic L, Markovic-Pekovic V, Skrbic Ret al. Recent Initiatives in the Republic of Srpska to Enhance Appropriate Use of Antibiotics in Ambulatory Care; Their Influence and Implications. Frontiers in pharmacology. 2018;9:442.

71. Dar OA, Hasan R, Schlundt J et al. Exploring the evidence base for national and regional policy interventions to combat resistance. Lancet. 2016;387(10015):285-95.

72. Chuc NT, Larsson M, Do NT et al. Improving private pharmacy practice: a multi-intervention experiment in Hanoi, Vietnam. Journal of clinical epidemiology. 2002;55(11):1148-55.

*An early study documenting the impact of multiple interventions to reduce self-purchasing of medicines including antibiotics for respiratory infections

73 Mukokinya M, Opanga S, Oluka M et al. Dispensing of antimicrobials in Kenya: A crosssectional pilot study and its implications. Journal of Research in Pharmacy Practice. 2018;7(2):77-82.

74. Hadi MA, Karami NA, Al-Muwalid AS et al. Community pharmacists' knowledge, attitude, and practices towards dispensing antibiotics without prescription (DAwP): a cross-sectional survey in Makkah Province, Saudi Arabia. International journal of infectious diseases. 2016;47:95-100.

75. Chang J, Ye D, Lv B et al. Sale of antibiotics without a prescription at community pharmacies in urban China: a multicentre cross-sectional survey. The Journal of antimicrobial chemotherapy. 2017;72(4):1235-42.

76. Eslami N, Eshraghi A, Vaseghi G et al. Pharmacists' Knowledge and Attitudes Towards Upper Respiratory Infections (URI) in Iran: A Cross Sectional Study. Rev Recent Clin Trials. 2016;11(4):342-5.

77. Jacobs TG, Robertson J, van den Ham HA et al. Assessing the impact of law enforcement to reduce over-the-counter (OTC) sales of antibiotics in low- and middle-income countries; a systematic literature review. BMC health services research. 2019;19(1):536.

**Good systematic review documenting the impact of law enforcement to reduce self-purchasing of antibiotics

78. Robertson J, Iwamoto K, Hoxha I et al. Antimicrobial Medicines Consumption in Eastern Europeand Central Asia - An Updated Cross-National Study and Assessment of QuantitativeMetrics for Policy Action. Frontiers in pharmacology. 2019;9(1156).

79. Turkish Medicines And Medical Devices Agency. Pharmaceutical Track And Trace System (ITS). 2019. Available at URL:

https://www.gs1.org/sites/default/files/docs/healthcare/2019.Noordwijk/Presentations-

Day3/02.Day3Turkish-pharmaceutical-track-trace-system-ITS.pdf.

80. Ministry of Health and Social Security Albania. Barnat pa recetë, intensifikohen kontrollet në farmaci. October 2018. Available at URL: http://www.shendetesia.gov.al/barnat-pa-receteintensifikohen-kontrollet-ne-farmaci/.

81. Ministry of Health and Social Security Albania. Manastirliu ngre "Task Forcë" për kontrollin e barnave. September 2018. Available at URL: http://www.shendetesia.gov.al/manastirliu-ngre-taskforce-per-kontrollin-e-barnave/.

82. Santa-Ana-Tellez Y, Mantel-Teeuwisse AK, Dreser A, Leufkens HG, Wirtz VJ. Impact of overthe-counter restrictions on antibiotic consumption in Brazil and Mexico. PloS one. 2013;8(10):e75550.

83. Godman B, Fadare J, Kibuule D, Irawati L et al. Initiatives Across Countries to Reduce Antibiotic Utilisation and Resistance Patterns: Impact and Implications. In: Arora G, Sajid A, Kalia VC, editors. Drug Resistance in Bacteria, Fungi, Malaria, and Cancer. Cham: Springer International Publishing; 2017. p. 539-76.

84. Moura ML, Boszczowski I, Mortari N et al. The Impact of Restricting Over-the-Counter Sales of Antimicrobial Drugs: Preliminary Analysis of National Data. Medicine. 2015;94(38):e1605. 
85. Lopes-Junior R, de Sa Del Fiol F, Araujo JL et al. Decrease in penicillin Sales in Brazil after over-the-counter restrictions. Antimicrob Agents Chemother. 2015;59(9):5862-3.

86. Wirtz VJ, Herrera-Patino JJ, Santa-Ana-Tellez Y et al. Analysing policy interventions to prohibit over-the-counter antibiotic sales in four Latin American countries. Trop Med Int Health. 2013;18(6):665-73.

87. Vacca CP, Nino CY, Reveiz L. [Restriction of antibiotic sales in pharmacies in Bogota, Colombia: a descriptive study]. Revista panamericana de salud publica. 2011;30(6):586-91. 88. Santa-Ana-Tellez Y, Mantel-Teeuwisse AK, Leufkens HG et al. Seasonal Variation in Penicillin Use in Mexico and Brazil: Analysis of the Impact of Over-the-Counter Restrictions. Antimicrobial Agents and Chemotherapy. 2015;59(1):105-10.

89. Kamati M, Godman B, Kibuule D. Prevalence self-medication in acute respiratory infections in the informal settlements in Outapi Region, Namibia. MURIA 4; 2018: 37. Available at URL:

file:///C:/Users/mail/Downloads/Consolidated-abstract-booklet\%20(4).pdf.

90. Kamati M, Godman B, Dan Kibuule D. Prevalence of self-medication for acute respiratory infections in Namibia; findings and implications. 2019. Accepted for publication Journal of Research in Pharmacy Practice.

91. Markovic-Pekovic V, Grubisa N. Self-medication with antibiotics in the Republic of Srpska community pharmacies: pharmacy staff behavior. Pharmacoepidemiol Drug Saf. 2012;21(10):1130-3. 92. Versporten A, Bolokhovets G, Ghazaryan L et al. Antibiotic use in eastern Europe: a crossnational database study in coordination with the WHO Regional Office for Europe. The Lancet Infectious diseases. 2014;14(5):381-7.

93. Bin Nafisah S, Bin Nafesa S, Alamery AH, et al. Over-the-counter antibiotics in Saudi Arabia, an urgent call for policy makers. Journal of infection and public health. 2017;10(5):522-6.

94. Ministry of Health Saudi Arabia. MOH starts implementation of law enforcement to prohibit dispensing antibiotics without valid medical prescription (in Arabic) 2018. Available from: https://www.moh.gov.sa/Ministry/MediaCenter/News/Pages/news-2018-05-06-001.aspx.

95. Creswell JW. Controversies in mixed-methods research. 2007. Chapter 15, ps 269-283.

Available at URL: https://www.sagepub.com/sites/default/files/upm-binaries/40426_Chapter15.pdf

96. Grimm P. Social Desirability Bias. Wiley International Encyclopedia of Marketing2010.

97. Ibrahim MI, Palaian S, Al-Sulaiti F, et al. Evaluating community pharmacy practice in Qatar using simulated patient method:acute gastroenteritis management. Pharmacy practice.

2016;14(4):800.

98. Siang TC, Hassali MA, Saleem F et al. Assessment of medicines price variation among community pharmacies in the state of Penang, Malaysia by using simulated client method. Journal of Medical Marketing. 2014;14(2-3):115-24.

99. Zawahir S, Lekamwasam S, Aslani P. Antibiotic dispensing practice in community pharmacies: A simulated client study. Research in Social and Administrative Pharmacy. 2019;15(5):584-90.

100. Gebretekle GB, Serbessa MK. Exploration of over the counter sales of antibiotics in community pharmacies of Addis Ababa, Ethiopia: pharmacy professionals' perspective. Antimicrobial resistance and infection control. 2016;5(1):2.

101. Zawahir S, Lekamwasam S, Aslani P. Community pharmacy staff's response to symptoms of common infections: a pseudo-patient study. Antimicrob Resist Infect Control. 2019;8:60.

102. Alaqeel S, Abanmy NO. Counselling practices in community pharmacies in Riyadh, Saudi Arabia: a cross-sectional study. BMC health services research. 2015;15(1):557.

103. General Authority for Statistics - Kingdom of Saudi Arabia. Population of Qassim region by gender, age group and nationality- Mid 20182018 [Available from: https://www.stats.gov.sa/ar/10070 .

104. General Authority for Statistics - Kingdom of Saudi Arabia. 2017 Guide to services (16th Version) to Qassim Region 2017.

105. Ministry of Health Saudia Arabia. Annual Report of the Ministry of Health 2017 [Available from:

https://www.moh.gov.sa/Ministry/About/Documents/MOH ANNUAL BOOKLET 2017\%20FINAL\%2 $0(1) \cdot p d f$

106. Al Akshar SA, Shamssain M, Metwaly Z. Pharmacists' perceptions of community pharmacy practice in UAE: An Overview. IOSR Journal of Pharmacy. 2014;4(6):47-56.

107. Ministry of Health. Kingdom Saudi Arabia National Action Plan On Combating Antimicrobial Resistance 2017 [Available from:

http://www.bsac.org.uk/antimicrobialstewardshipebook/Chapter\%2015/National-AMR-Plan-2017.pdf. 108. Uniazah College of Pharmacy (UCP) QU. Annual report 2019. 
109. Leung E, Weil DE, Raviglione M et al. The WHO policy package to combat antimicrobial resistance. Bull World Health Organ. 2011;89(5):390-2.

110. Amin MEK, Amine A, Newegy MS. Perspectives of pharmacy staff on dispensing subtherapeutic doses of antibiotics: a theory informed qualitative study. International journal of clinical pharmacy. 2017;39(5):1110-8.

111. Saengcharoen W, Chongsuvivatwong V, Lerkiatbundit $S$ et al. Factors influencing dispensing of antibiotics for upper respiratory infections among Southern Thai community pharmacists. Journal of clinical pharmacy and therapeutics. 2008;33(2):123-9.

112. Siddique H. NHS patients waiting over two weeks to see a GP, shows survey. 2019. Available at URL: https://www.theguardian.com/society/2019/aug/12/nhs-patients-waiting-over-two-weeks-tosee-a-gp-shows-survey.

113. Alfadl AA, Alrasheedy AA, Alhassun MS. Evaluation of medication counseling practice at community pharmacies in Qassim region, Saudi Arabia. Saudi Pharmaceutical Journal.

2018;26(2):258-62. 